\title{
Effects of Peer Scaffolding on Students' Grammar Proficiency Development
}

\author{
Addisu Alehegn Abune \\ Debre Markos University College of Social Science and Humanities Department of English Language and \\ Lierature:Debre Markos,Ethiopia,SJune, 2019
}

\begin{abstract}
The main purpose of this study was to examine the effect of Peer Scaffolding on students' grammar proficiency development. The recently developed model under study -Peer scaffolding- is based on Vygotsky's and Leentevo's Scaffolding instruction. To put the model in to practice an intervention program was designed and implemented. The program had two components Experimental and Control group .The sample consisted of $\mathbf{1 0 2}$ grade eleven students in two classes at Tillili Preparatory and General Secondary School. The classes were randomly assigned into experimental and control groups. A non equivalent group pre- test-post- test quasi experimental design was employed with $\mathbf{5 2}$ experimental and $\mathbf{4 9}$ control participants. Two grammar proficiency tests (one pre test and one post test) were designed. Both experimental and control groups were involved in similar scaffolding grammar proficiency activities for two months. The experimental group learned grammar activities using the peer scaffolding instruction. The control group, on the other hand, learned grammar the same exercise within the same period of time working with the teacher who was not trained in peer scaffolding. At the post intervention phase, the other tests followed by the social validity questionnaires were administered. The findings revealed that the Experimental group showed greater pre- to post- intervention improvement in grammar proficiency and show the intervention as socially valid. Thus, the study corroborated the efficacy of Peer Scaffolding intervention as feasible tool to enhance grammar proficiency development.
\end{abstract}

Keywords: Grammar proficency,Scaffolding,Social validity

DOI: $10.7176 / J L L L / 58-02$

Publication date:July $31^{\text {st }} 2019$

\subsection{Introduction}

Whenever we are dealing with the issues of second language pedagogy and learning theories, we are, partly, concerned about the grammatical aspects of the target language. As a matter of fact, the grammar of a language is the main backbone of a language up on which the entire language system is built. As a flesh of human beings or other animals cannot stand alone without the presence and healthy system of their skeleton (set of bones); in most cases a collection of content words cannot make a meaningful communication unless they are combined with the right forms and structural words. This is the major rationale for the inclusion of grammar in second language teaching and learning process. As Sysoyev (1999) quoted Encyclopedia of Applied Linguistics, "Communication cannot take place in the absence of structure, or grammar, a set of shared assumption how language works..." This is because grammar is a means by which we organize messages to convey meaningful communication (Nuru, 1996).To emphasize this point, let us think of the proportion of English content words and structural words. It seems that content words in English take the lion's share of English language word stock. However, making meaning out of them may probably be difficult without consideration of structural words. Thus, the issue of grammar becomes worth and very critical in ELT. This does not mean that we have to give little attention or ignore other language skills, which are equally important.

However, with the introduction of communicative language teaching approach (CLT), it seemed that grammar was given little attention in second language pedagogy. This could be because, as Dickens and Wood (1988) pointed out, there has been confusion about the importance of grammar for communication. Grammar and communication were perceived as two independent features, rather than as two basic elements necessary for effective language use. Due to the above misconception, as Celce-Murcia (1992) cited Eskey (1983), there is now a belief that if students learn to communicate, mastery of the form will take care of itself (the reverse was true before the introduction of CLT) Ibid.

However, as Eskey (1983) suggested, "the form does not take care of itself".It is difficult to teach students how to communicate without having the key tools for communication. Regarding this view, Celce-Murcia (1992) stated, "we claim that linguistic accuracy is as much a part of communicative competence as being able to get one's meaning across or to communicate in a socio-linguistically appropriate manner" (p.208) The point from the discussion we have so far is that the inclusion of grammar is crucial in ELT. But, the way it is taught is the basic question which may narrow down the central issue of the debate that has been existent for ages.

In the history of ELT, there have been two broad methods of grammar teaching. One is a form-focused grammar teaching and the other (recent) is a meaning-focused grammar teaching approaches, or as Harmer (1987) classified, covert and overt grammar teaching methods. As to the question of effectiveness of the methods, 
(Prabhu, 1987) claims that it is determined based on the goals and needs of learners. If the students need grammar for communication, meaning based grammar teaching approach will be effective.

However, if the students need grammar for translating L2 to L1, then form-based grammar teaching will be effective. Nevertheless, as the very goal of the current second language learning and teaching process is developing learners' communicative competence, meaning-focused grammar teaching is believed to be relatively effective. As many researchers conducted in our country showed, meaning focused grammar teaching approach is effective and functional. Many of the researches were conducted in Addis Ababa University, among these; Hailom Banteyerga (1982), Gebremedhin Simon (1984), Worede Yishak (1986), Geremew Simu (1994) and Dereje Tadesse (2001) as cited in Abraham( 2008 ) are some of the researchers who had conducted a study in connection to the teaching and learning of grammar in Ethiopian context.

The purpose of the study which was conducted by Hailom Banteyerga (1982) was to compare the effectiveness of communicative approach Vs the structural approach in the teaching of English conditional sentences. Accordingly, the finding of the study showed that the students who were taught through communicative approach had scored better performance than those of students who were taught through structural approach. In the same way, the study which was conducted to see the effectiveness of structural versus the form-function approach in the teaching of English modals, by Worede Yishak (1986), revealed that the formfunction approach is relatively effective. Other researches, 'Contextualizing structural based exercises,' by Getachew Fantaye(1984); 'The effectiveness of language acquisition approach versus conscious-rule learning approach,' by Gebremdhin Simon (1984) and other findings revealed a positive result in favor of communicative language teaching approach. Thus, the above stated researchers recommended the use of context, and meaningbased or/and communicative approach for the teaching of grammar. Although this is what the literature and the research findings recommended, many English grammar teachers of Ethiopian high schools and students are still in the system of the old structural grammar teaching and learning method. (Dereje Taddesse, 2001). Besides, Walter (1997) stated, "Although the need for contextualization in ESL grammar instruction has long been recognized, a great deal of traditional teaching methodology in this area still persists." (p. 201).

The rationale for using context is so as to familiarize students with the meaning and use aspects of a given form. It is with this assumption that the present researcher proposed to conduct a study on the effectiveness of peer scaffolding in grammar instruction classroom.

\subsection{Statement of the Problem}

It is important to have the knowledge and skill of grammar for meaningful communication. People may not pass the intended message meaningfully unless they arrange words in at least their minimum acceptable order. For this reason, grammar is viewed as the central area of a language around which skills like reading, writing, speaking, vocabulary and other components of a language such as meaning and function revolve (Ur, 1988). Of course, grammar by itself as an end product of a language may not be as such important, but it plays a key role in communication. For example, when we request, invite, or order people to do something, we use grammar as a means of passing the intended message. In relation to this, Cook (2001: 20) says "Grammar is sometimes called the computational system that relates sound and meaning trivial in itself but impossible to manage without". Again, Batstone (1994: 3) on his part argues that "Language without grammar would certainly leave us seriously handicapped". The reason for this is that language is broad and we manage it because there are a set of rules that govern how units of meaning are constructed. Hence, teaching foreign language grammar has a paramount importance for good command of the foreign language where there is no natural way of acquiring the language (Ibid).

In spite of the fact that teaching English grammar is essential, the teaching methods and techniques employed in a classroom can have either negative or positive effect on the development of communicative competence of the learner. More specifically, if the method becomes effective and enjoyable, the form and meaning can be understood easily. On the other hand, if the methods are not effective and enjoyable, students may fail to understand and use the structure. In short, the types of grammar teaching methods and techniques used by language teachers can affect not only grammar skill but also the development of other language skills (speaking, reading, listening etc) and the overall language performance of learners (Cunningsworth, 1984). It is because of this reason that the researcher wanted to conduct research on grammar teaching methods.

In the past, experience showed that Ethiopian students were being taught grammar using the traditional approach. Teachers were teaching the rules of the language through explicit explanation using examples. After the explanation, students most of the time were told to construct their own sentences similar to the example. The researcher himself is the product of that method. But, scholars such as Cunningsworth (1984) and McDonough and Shaw (1993) criticize this kind of instruction for it brings fragmented and unrealistic language items besides discouraging classroom interaction. Believing that the main purpose of language is communication, the present Ministry of Education has changed the old method to a new method by introducing task based language instruction that fosters peer or teacher scaffolding. The program designers believed that teaching English 
language by scaffolding would enhance learner participation (Seyum, 2008).

This study, therefore, attempts to check the effect of peer scaffolding on the development of grammar teaching in relation to the theory of communicative grammar teaching.

\subsection{Objectives of the study}

The purpose of this study was examining the efficacy of alternative reading instructional programme. More specifically the study attempted to:

examine the effect of peer scaffolding on scaffolders' grammar instruction; and recognize the students' appraisal of the social validity of peer scaffolding programme.

\section{LITERATURE REVIEW}

\subsection{Over view of scaffolding}

The concept of scaffolding has its origins in the work of the psychologist Vygotsky as well as in studies of early language learning. Bruner (1978) believed that for learning to take place, appropriate social interactional frameworks must be provided. In the case of the young child learning language, the instructional component consists of the caregiver (normally the mother) providing a framework to allow the child to learn. To do this, the caregiver should always be one step ahead of the child (Vygotsky's zone of proximal development), and by using contexts that are extremely familiar and routinized the caregiver can facilitate the child's learning. These highly predictable routines, such as reading books together or conversations at bath time or meals, offer the caregiver and child a structure within which the caregiver can continually raise her expectations of the child's performance. For Bruner, this meant specifically the child's linguistic performance, because, he argued, it is within these formats that children learn how to use language. Cazden (1983) adopted Bruner's use of the term scaffolding, but distinguished between vertical and sequential scaffolding.

Vertical scaffolding involves the adult extending the child's language by asking further questions. So in response to the child's utterance 'cow', she might say 'Yes, that's a cow. What does the cow say?', or she might ask for an elaboration 'And what did we see when we went to the farm today?'

Sequential scaffolding is the scaffolding found in the games played with children at meals, bath times, and so on. Applebee and Langer (1983) used the notion of instructional scaffolding as a way to describe essential aspects of formal instruction. In their view, learning is a process of gradual internalization of routines and procedures available to the learner from the social and cultural context in which the learning takes place. In instructional scaffolding the language learner is assisted in a new task by a more skilled language user who models the language task to be used verbally and/or in writing. As well as through modeling, scaffolding is provided by leading or probing questions to extend or elaborate the knowledge the learner already possesses. Rather than evaluating the learner's answers, the teacher is supporting, encouraging, and providing additional props. As the learner's competence grows, so the scaffolding is gradually reduced until the learner is able to function autonomously in that task and generalize to similar circumstances.

There are five criteria for effective scaffolding (Applebee 1986):

1. Student ownership of the learning event. The instructional task must allow students to make their own contribution to the activity as it evolves.

2. Appropriateness of the instructional task. This means that the tasks should build upon the knowledge and skills the student already possesses, but should be difficult enough to allow new learning to occur.

3. A structured learning environment. This will provide a natural sequence of thought and language, thus presenting the student with useful strategies and approaches to the task.

4. Shared responsibility. Tasks are solved jointly in the course of instructional interaction, so the role of the teacher is more collaborative than evaluative.

5. Transfer of control. As students internalize new procedures and routines, they should take a greater responsibility for controlling the progress of the task such that the amount of interaction may actually increase as the student becomes more competent.

For Applebee, one of the most appealing features of these principles is that they provide a new way to think about familiar teaching routines, rather than a wholesale abandonment of the past.

Other views on scaffolding, such as Long and Sato (1984) see conversational scaffolding, in particular, as the crucible of language acquisition. Hatch (1978) cited in Applebee (1986) has also argued that language learning evolves out of learning how to carry out conversation and that syntactic constructions develop out of conversation. Rather than assuming that the learner first learns a form and then uses that form in discourse, Hatch assumes that the learner first learns how to do conversation, how to interact verbally, and out of this interaction syntactic forms develop. Specifically in building a conversation with a partner (vertical construction), the learner establishes the prototypes for later syntactic development (horizontal construction). However, Sato (1986) makes the point that even if the collaborative discourse of scaffolding is credited with making a positive contribution to syntactic structures, what is difficult to determine is the role played in the acquisition of 
morphological features (such as the regular past tense). It is possible that collaborative discourse plays a significant part in early acquisition, but it is doubtful whether all interlanguage rules can emerge in this way.

\subsection{Scaffolding - Related Theory, Theorists, and Research}

Scaffolding instruction as a teaching strategy originates from Lev Vygotsky's sociocultural theory and his concept of the zone of proximal development (ZPD). Lev Vygotsky was a Soviet psychologist whose works were surpressed after his death in the 1930s and were not discovered by the West until the late 1950s ("Lev Vygotsky's archive," n.d.). His sociocultural theory proposes that social interaction plays a fundamental role in the development of cognition. ("Social Development Theory," n.d.). Vygotsky “...theorized that learning occurs through participation in social or culturally embedded experiences." (Raymond, 2000, p. 176). In Vygotsky's view, the learner does not learn in isolation. Instead learning is strongly influenced by social interactions, which take place in meaningful contexts. Children's social interaction with more knowledgeable or capable others and their environment significantly impacts their ways of thinking and interpreting situations. A child develops his or her intellect through internalizing concepts based his or her own interpretation of an activity that occurs in a social setting. The communication that occurs in this setting with more knowledgeable or capable others (parents, teachers, peers, others) helps the child construct an understanding of the concept (Bransford, Brown, \& Cocking, 2000) ac cited in Applebee 1989. The communication helps the child develop inner or egocentric speech. The inner speech is abbreviated speech for oneself that eventually directs personal cognitive activities. Inner speech is developed as the adult initially models a cognitive process and communicates the steps as in "think-aloud" modeling. "...Over time and through repeated experiences, the child begins to internalize, and assumes responsibility for the dialogical actions, (i.e. it becomes a "private speech" spoken aloud by the child to direct personal cognitive activity)." (Ellis, Larking, Worthington, n.d., Principle 5 Research section, para.3). In subsequent similar activities the amount and or type of modeling and guidance provided by the more knowledgeable other will be reduced until the child is able to complete the activity without these supports or scaffolds, the child's inner speech would now be directing the child's activities. ("Four Stage Model," n.d. and Jaramillo, 1996).

The second foundation for scaffolding instruction is Vygotsky's concept of the zone of proximal development (ZPD). The ZPD “... is that area between what a learner can do independently (mastery level) and what can be accomplished with the assistance of a competent adult or peer (instructional level)" (Ellis, Larkin, Worthington, n.d. Principle 5, Research section, para.1). Vygotsky believed that any child could be taught any subject effectively using scaffolding techniques by applying the scaffolds at the ZPD. "Teachers activate this zone when they teach students concepts that are just above their current skills and knowledge level, which motivates them to excel beyond their current skills level" (Jaramillo, 1996, p. 138). Students are guided and supported through learning activities that serve as interactive bridges to get them to the next level. Thus the learner develops or constructs new understandings by elaborating on their prior knowledge through the support provided by more capable others (Raymond, 2000). Studies have actually shown that in the absence of guided learning experiences and social interaction, learning and development are hindered (Bransford, Brown, and Cocking, 2000) .(Ibid)

Modern research continues to find that scaffolding is an effective teaching strategy. Two recent studies regarding the use of inscriptions for teaching scientific inquiry and experimentation (external representations graphs, tables, etc.) found that the use of external representations, representational scaffolds, can serve as an effective strategy for teaching these scientific skills. In one study the instructional goal was to teach fourth graders valid experimentation skills. During the first part of the study a teacher-specified table of variables was the scaffold provided. Students had to select the appropriate variable related to their experiment. The results of this part of the study led to the conclusion that the "... use of the pre-developed table representation may have helped students abstract the overall structure of the experiment and thus aided their understanding of the design..." (Toth, Results and Discussion section, para. 1). The teacher designed table helped focus the learners' thinking on only those items that were important for the task. Additionally through the use of the table it became obvious to the students if they had omitted an important variable from their experiment. This helped the students learn what things must be considered when designing an experiment (Toth, n.d.).

In the second study, “.. the effects of two different external representations (evidence mapping vs. prose writing)..." were evaluated in research with ninth grade students (Toth, n.d., Representational scaffolding while coordinating data with theories section, para. 1). Students used either a software tool or prose writing to record their thinking during a problem-based-learning activity in which they had to find a solution to a scientific challenge. The software tool provided epistemological categories linked with unique shapes. The students that used the software had to categorize the information they were evaluating by selecting the appropriate shape and entering the information into the shape. The students in the prose writing group just documented their thinking by writing. One finding of the study was that the students who used the software tool correctly categorized more of the information as hypothesis and data than those students in the prose writing groups. The correct 
categorization of information was attributed to "...the effect of the mapping representation that scaffolded students' categorization efforts" (Toth, n.d., Results and Discussion section, para. 1). Eva Toth concluded from the research that the use of , "...teacher-developed table representations was found to scaffold students' progress of inquiry by making the variables of an experiment salient and by perceptually constraining the students' attention to abstract the characteristics of correct experimentation" (Toth, n.d.)

Kuo-En Chang, Yao-Ting Sung, and Ine-Dai Chen conducted a study to test the learning effects of three concept-mapping methods on students' text comprehension and summarization abilities and "...to determine how students can most effectively learn from concept mapping" (Chang, Chen, \& Sung, 2002, p. 8). For the study three concept-mapping methods were designed "...with varying degrees of scaffolding support, namely, map construction by correction (with constant and highest degree of scaffolding), by scaffold fading (with gradually removed scaffolding), and by generation (with the least scaffolding)" (Chang, Chen, \& Sung, 2002, p. 19). The 7 week study was conducted with 126 fifth grade students that were randomly assigned to 4 groups, one for each concept mapping method and a control group. Both pre- and post- text comprehension and summarization tests were administered to evaluate the students' abilities. Each group received the same reading materials and training on concept mapping. The map correction group was given a partially revised expert generated concept map that included some incorrect information. The students had to read the provided materials before correcting the errors in the map. The instruction for the scaffold-fading group consisted of the following: "...(a) read an expert concept map, (b) fill in the blanks of the expert concept map (with whole structure), (c) complete the partial expert concept map (with partial structure), (d) construct the concept map using the given concepts and relation links, and (e) determine the key concepts and relation links from the text to construct the concept map" (Chang, Chen, \& Sung, 2002, p.10). Only the reading materials were provided to the students in the map generation group.

The study results showed that the map-correction group performed better on the text comprehension and text summarization posttests than did the scaffold-fading or other groups. It also found that the scaffold-fading group performed much better than the map-generation and control groups on the text summarization posttest but showed no significant difference on the text comprehension posttest (Chang, Chen, \& Sung, 2002). The authors explain that the students in the map-correction group performed better because the map-correction scaffolding provided a content framework for and a reminder of the content in the text. The authors go on to explain that the finding regarding the scaffold fading group was not consistent with the findings of “...Day and Cordon (1993) and Kao (1996) that the scaffolding instruction method had better direct and transferring effects than general teaching methods..."(Chang, Chen, \& Sung, 2002, p. 20). They cite two factors that may have affected the outcome of their study and generated the inconsistent findings. First, they state that, "... the operations performed after the scaffolding was removed may still have been too difficult for elementary school students" and secondly there "... may have been the lack of sufficient time for training" (Chang, Chen, \& Sung, 2002, p. 20).

They conclude that the scaffolds provided by the map-correct method (framework and partial information) seem "...to be a more suitable way for conducting concept mapping for elementary students" (Chang, Chen, \& Sung, 2002, p. 19) than the other methods, scaffold-fading or map generation. However any form of concept mapping (scaffolding) “... may serve as a useful graphic strategy for improving text learning” (Chang, Chen, \& Sung, 2002, p. 21).

Scaffolding instruction guides the learner to independent and self-regulated competence of skills. This occurs when the learner's inner speech occurs on an automatic, unconscious level (Ellis, Larkin, Worthington, n.d.). In addition to improving learners' cognitive abilities, scaffolding instruction in the context of classroom learning and student research:

1. Delivers efficiency - Since the work is structured, focused, and glitches have been reduced or eliminated prior to initiation, time on task is increased and efficiency in completing the activity is increased.

2. Creates momentum - Through the structure provided by scaffolding, students spend less time searching and more time on learning and discovering, resulting in quicker learning (McKenzie, 1999).

\subsection{Historical Overview of Grammar}

Language teaching, particularly grammar teaching, has a long history. According to Stern (1983: 131), grammar was taught beginning from the classical era. It was also taught during the middle ages in the 12 th $-15^{\text {th }}$ centuries. During that time the traditional language school, which was dominated by Latin and Greek language learning philosophy, was considered primarily as the study of its grammar.

In the grammar translation method, grammar was given due attention and was considered both as an end by itself and also as a means to enable the learner to read and write. In the first half of the 20th century, structural linguists gave attention to grammar teaching. The structural view to language teaching placed grammar in the center of language learning and teaching. It viewed language mainly as a system of structurally related elements 
for the coding of meaning.

In other words, structural linguists emphasize the idea that language learning should be seen in terms of the mastery of the elements in the grammar system (that is, phonological units, grammar units, and lexical items). According to the structural view, the mastery of the elements of grammar provides the learner an opportunity to effective preparation for the realization of communication ( Richards and Rodgers, 2001).

In the late 1950s, grammar was considered as unscientific and unworthy while linguistics was given a higher consideration. In other words, the coming of communicative approach to language teaching brought a negative reaction against explicit grammar teaching in schools. As a result, in the first half of the 20th century teaching grammar knowledge as a focus and translation as a means was overlooked by those scholars who began to see grammar teaching as the transmission of the grammatical system in context (Martin, 1994). Harmer's expression about the changing status of grammar in the history of language teaching is evidence to this If grammar were a person it might be actor whose popularity fluctuated widely over the decades as he or she got good roles, then made some bad movies, then was rediscovered, then disappeared for a bit only to be suddenly cast in leading roles again. If grammar were a style of clothing, it would probably be flared trousers, popular in the $1920 \mathrm{~s}$ and 30s, then abandoned then popular again in the 60s and 70s, then abandoned conclusively and completely but now a modest comeback. Grammar, in other words, is a fashion victim (Harmer, 1998 in Englis

\subsection{Arguments against Grammar Teaching}

The arguments against grammar teaching come from different views about language. The first argument comes from the views that language is a set of skills. To elaborate the point, they equate language learning with learning to ride a bike. Someone may have the information or the knowledge about the activities and the basic steps involved in riding a bike, such as: keeping your balance, pedaling, steering by means of the handlebars and so on. But, this does not guarantee that one knows how to ride or can ride a bike. The same idea works for language learning. One may have a good knowledge of grammar; however, it does not necessarily mean that he/she can be fluent user of the language. One piece of evidence to support this view is the inability or inefficiency of structural approach of language teaching to produce learners who use the target language for their communication needs.

Thus, from the skill point of view, we learn language by doing it. In other words, it is by means of experiential learning that one can learn a language rather than by studying it. Proponents of this view, suggest that L2 learners should not be exposed to an explicit grammar learning rather there should be a situation where in students can use the target language to communicate their ideas, opinions and feelings each other. Thornsbury (1999 cited in Seyum)

The second major argument (according to Thornsbury, 1999) that discredits the weight given for grammar teaching comes from the goal of language learning. As frequently heard, communicative competence is the end goal of second language learning. Here, linguistic competence is considered as one element of communicative competence among other components. As to the learning process, there are two different views. The first view, which is advocated by the adherents of the weak version of CLT, suggests that we learn a language in order to use it and accordingly, language learners should learn the rules first and then engage themselves in a life like communication in order to apply what they have learned. However, as opposed to this point, scholars who are the leading followers of the strong version of CLT believed that L2 learners can acquire a language by communicating or by using the language. In other words, some call it, learning by doing or experiential learning. Due to such belief, explicit grammar teaching is considered 'unhelpful' and a 'waste of time' (Thornsbury, 1999).The other source of the argument against grammar teaching is connected with the theory of first language acquisition. Thornsbury (1999:19) questioned, "The fact that we all learned our first language without being taught grammar rules has not escaped theorists. If it works for the first why shouldn't it work for the second?" The origin of this view comes from the well known applied linguist Stephen Krashen. Krashen has made the distinction between learning and acquisition. For him, learning is achieved through tutored/formal/ instruction, like learning grammar rules, which is incapable to make L2 learners use the target language for communication. However, acquisition is a natural process that can be achieved through the communicative interaction made with the speakers of the language, as what happen in the process of first language acquisition. Therefore, acquisitions (the sole means of L2 success) can occur when learners are exposed to a rich variety of comprehensible input in a stress-free environment which can trigger learners' innate capacity. (ibid)

In a similar way, Prabhu (1987) as cited in Richards and Renandya (2002:67) argued, "classroom learners can acquire an L2 grammar naturalistically by participating in meaning focused tasks." The last argument that favors the exclusion of grammar from second language pedagogy is associated with the theory of universal grammar. The famous linguist, Noam Chomisky believed that language ability is not a learned/habituated behavior. Rather it is through an innate human capacity that one can acquire a language. Chomsky (as reported by Thornsbury: 1999) argued, "Human beings are 'hard-wired' to learn a language. That is, there are universal principles of grammar that we are born with." 
According to Chomsky, formal grammar teaching has nothing to do with language acquisition as there is the natural order of acquisition of grammatical items. The grammar that L2 learners learn in language classroom cannot replace the 'mental grammar' and so that formal classroom's grammar instruction is a waste of time. (Thornsbury 1999). Despite all these opposite views and arguments against the relevance and the inclusion of grammar in second language pedagogy, there are also a number of strong arguments in favor of the inclusion of grammar and its centrality in the entire foreign language learning and teaching process.

\subsection{Arguments in favor of Grammar Teaching}

In the last section we have seen some of the arguments against the inclusion of grammar teaching in ELT. At the same time there are also strong claims that favor the need to incorporate grammar teaching as one part of second language pedagogy. Below are some of the arguments.

The first and foremost argument which tries to put grammar teaching at the forefront of second language teaching and learning process comes from the view that-grammar is 'a sentence making machine' (Thornsbury 1999). In the word stock of English language, the content words comprise the highest percentage of the total words and the remaining are structural or grammatical words (Cook, 2001).

However, unless one has the necessary knowledge about how structural words combine with content words to convey meaning; it is mostly very difficult to communicate only by using content words. In support of this argument, Azar (2007) suggested that grammar helps learn to discover the general feature of a language. Language consists of predictable patterns that make what we say, read, hear and write intelligible. Without grammar, we would have individual words or sounds, pictures, and body expression to communicate meaning. Grammar is the weaving that creates the fabric (Azar 2007:3). Azar (2007), in connection with the views that exclude grammar teaching from second language teaching and learning process, strongly argues that those who were prominent in the naturalist approach (Krashen) were mistaken in advocating zero grammar. In a similar way, Cunningworth, 1984; Cecle-Murcia, 1991; Widdowson, 1990; Lock, 1996 noted that the question whether to include grammar in second language teaching pedagogy is not a debatable issue. It is not optional since it is one of the key elements necessary for effective communication to take place. As Cook (2001:19) depicted, "Grammar is sometimes called the computational system that relates sound and meaning's trivial in itself but impossible to manage without."

The second view that favors grammar instruction comes from the 'fossilization' argument. Thorns bury (1999:24) reported, "More recently researchs suggest that without some attention to form, learners run in the risk of fossilization." In a similar way, Larsen-Freeman (1992) notes that excluding the teaching of syntax is to open the door for linguistic competence fossilization. Azar (2007) in a similar way, states that there is nothing difficult than trying to explain certain grammatical structures and rules for students who knows nothing about the ideas of grammar. Such students' speaking and listening ability may be considered as fluent; however, their written English is full of ungrammatically.

Thus, there must be a grammar lesson that draws some attention to form. Azar (2007) notes that those learners (both native speaker and non-native speaker) who wish to use a language to the best of their ability, especially to do well in academic discourse, should have fundamental understanding of the target language grammar. Otherwise, it is very unlikely for learners to progress beyond the basic level of communication (Thornsbury, 1999).

The third point of argument that favors the inclusion of grammar in language teaching relate to the issue of 'noticing'. There is a view that grammar knowledge can serve as an 'advance organizer' which facilitates the language acquisition process. As the diary of Richard Schmidit (Researcher) has showed, the grammar lesson he had learnt previously helped him to become fluent Portuguese speaker while he was interacting with Brazilians. This is because he was noticing certain grammar features while communicating naturally. As a result, Schmidit concluded that noticing is a pre-requisite for acquisition. (Thornsbury, 1999; Ellis 1993).

In general, second language learners primarily should have the awareness about how the lexical and grammatical words combine to convey meaning. For the overall language progress (communicative competence) that is sought as the end goal of language learning and teaching program, grammar teaching should be part of it as it forms the basement of the system. Thus, as opposed to Krashen's (1982) and Prahbu's (1987) arguments, total negligent of grammar seems against the nature of a language. Both the form and the meaning are two fundamental and compulsory components of communication. We cannot think of language as a tool for communication with the absence of either form or meaning. Grammar knowledge is a necessary condition for communication to occur as it is the means to an end.

\section{Subjects and Sampling Technique}

The total population from which the samples were selected comprises 468 grade 10 students of the school enrolled in 2017/18. The students were grouped in 10 sections. Of this, sections B and E were selected. The sections were selected with simple random sampling (Bethelhem, 2009 p.101). Lot was casted to determine the 
comparison and the experimental groups. Consequently, section B students $(n=52)$ were put under comparison condition and section E students $(n=49)$ under experimental condition. All the students available in those sections were taken as subjects of the study.

\section{Instruments}

The peer scaffolding programme was an instrument or a means whereby the students' grammar instruction could be improved. Treatment materials were also the other instruments used during the intervention. There were two data collection instruments, which were employed to measure students' pre to post-grammar instruction.

\section{Peer scaffolding Programme}

The objective of the intervention programme was to improve students' grammar instruction. Peer scaffolding model, which was evolved from the integration of Vygotsky's theory, was guiding the intervention programme. The current intervention programme was designed to put the peer scaffolding model into practice. In line with this aim, the peer scaffolders were learning grammar with adequate scaffolding from trained peer scaffolders and the peer scaffolds were learning via helping the peer scaffolders. The teacher facilitates the learning process by meeting the scaffolders and the group in regular bases.

The intervention was characterized by two elements : a sound scaffolding preparation (training) and scaffolders' implementation of scffolding criteria in their interaction with scaffolders in bi-weekly peer scaffolded grammar instruction sessions.

The scaffolders were supposed to be able to assist classmates' learning in their ZPD through social interactions. They were agents of delivering adequate scaffolding. More importantly, they were expected to selfscaffold after taking training on the types of scaffolding.

\section{Peer scaffolders Training}

As peer scaffolding is less effective when little or no attention is paid to training of the scaffolders related to social interaction skills and the way of implementation of the types of scaffolding, a 24 hours training for students which enables them to be a good scaffolder was developed based on related research and peer scffolding programme. The trainings' core assumption was that teaching for peer scaffolding would elicit improved scaffolding skills from the scaffolders on one hand, and induce cognitive improvement in both learners and scaffolders on the other. Hence, the ultimate goal of the training was equipping the scaffolders' knowledge and skill with the types of scaffolding and their application to make them efficient scaffolder.

Verbal and visual explanations, modeling, discussions, and student practice with the trainer feedback represent an important part of the peer scaffolders training. The training was scheduled prior to the actual peer scaffolding grammar instruction sessions. Eight sessions were organized. The first session was aimed at introducing the scaffolders with the concept of scaffolding and its theoretical foundations.. In each session, the criterion was elaborated and lesson scenarios were discussed. The second session was practical session in which the scaffolders practice scaffolding their friends. The final session was wrapping up the types of scaffolding and talking about the way forward. The training was given by the researcher and a TEFL graduate from Addis Abeba university. Both trainers learned scaffolding strategies as a component of the course, 'Approaches to Language Teaching and Learning Theories' offered in the university they joined. More to this, they reviewed and synthesized literature concerning the theory of scaffolding prior to the training.

\section{Peer Scaffolding Sessions}

This intervention programme was rooted in social interactionism, which underlines the importance of interaction with other people. Williams and Burden (1997:39) saw in social interactionism, “... much theoretical underpinning to a communicative approach to language teaching." According to Williams (1984), communicative approach to language teaching suggests. Communicative lessons for teaching grammar according to Harmer (1991) should integrate the form and the meaning consisting of four equally important stages namely introduction, presentation, practice and production.

\section{Grammar Tests}

Since the primary purpose of the study was to see whether students' grammar skill can be improved as a result of the treatment, grammar tests were used. The researcher believes test was relatively the best tool to evaluate grammar instruction improvements. The researcher prepared six tests of which three were pre-tests and the other three were post-tests. The pre-tests were three in number for two reasons: (a) to get stable baseline that can be compared with the post-tests with confidence and (b) to successfully select the peer scaffolders and group leaders. Attempts were made to equalize the length and level of difficulty between and within the pre-tests and post-tests so that by comparing the two sets inferences can be drawn effectively. However, to minimize the testing effect the tests and the questions were varied. 
Each test consists of grammar lessons(tpoics) and thirty six questions. The questions were all multiple choice objective type questions. Subjective type questions were not used because they required the ability to organize and write. From experience, it was perceived that not all students were good at writing. This might aversively affect the validity of the results. Thus, only objective items were constructed based on the Pearson and Johnson (1978) classification of question type.The grammar activities were equivalent with the activities of the treatment lessons in level of difficulty.

The appropriateness of the activities used in the tests has been checked from different angles.Before pilot testing to measure the reliability, the tests were evaluated by two teachers holding MA degree and BEd. in English. Receiving the comments on content, item format and question types the items were re-written. The split half method was employed to measure internal consistency of the tests since this approach is much less susceptible to time-interval effects because all of the items were administered at the same time and then split into separate item pools afterward. Thus, the tests were administered for tweleve Burie preparatory and general secondary school $11^{\text {th }}$ grade students for pilot testing. The total questions of each test that purport to measure the students grammar proficiency were broken down into seven separate but equal sets of twenty five questions.

\section{Social Validity Questionnaire}

The purpose of questionnaire was to assess the perceived appropriateness and effectiveness of the intervention, feasibility of the procedures of the intervention, satisfaction and willingness of the participants to engage in similar programmes in other contexts. An eighteen-item questionnaire was designed after synthesizing the social validity questionnaires used by Udaka (2009); Oddo (2007) and Josephs (2010). Of the eighteen items, two of them asked the respondents whether the intervention was appropriate or not. Five items were about its effectiveness in making them become good reader, bring permanent change in reading performance and start to think, as they were capable of becoming good readers. The other five were related to the clarity, cost efficiency and manageability of the procedures. Three statements were concerning the enjoyment and satisfaction they get from participating in the intervention. The remaining three ask whether they were willing to participate in such intervention again and use such kind of intervention with other teachers changing their classroom routines.

Pilot testing the questionnaire to check its reliability was not implemented. Since students other than those who participated in the intervention could not fill the instrument, the only option was taking some students from the participants. This would have negative effects - minimizing the sample size of the main analysis and diffusion of information. Eventually, the reliability of the questionnaire was calculated by Cronbach's alpha and it was found to be 0.79 coefficient of reliability. This result indicates that the questionnaire has acceptable degree of reliability.

The scaffolding tool grammar proficiency was an instrument or a means whereby the students' speaking proficiency was developed. Treatment materials were also the other instruments used during the intervention. There were two data collection instruments, which were employed to measure students' pre- to- post- grammar proficiency development.

\section{Procedure}

\section{a. Experimental Procedure}

The experiment has two phases in which peer scaffolders were be trained and both scaffolders and scaffolds engage in practice. To achieve this, the peer scaffolders and the group leaders were selected based on their scores in the pre-tests. Each student's average score was computed from the test. Based on their average score the students were listed in descending order and eight high achieving students from the top of the list were selected to be peer scaffolders in the EG and group leaders in CG. The difference between the two groups was that only the scaffolders take peer scaffolding. The peer scaffolders took training in scaffolding techniques for two days.

As mentioned in section 3.1, the treatment was carried out for two months (from November $3^{\text {rd }}-$ January $2^{\text {nd }}$ ) in a couple of consecutive lessons every two weeks. Totally eight lessons were taught throughout the peer scaffolding programme practice phase. For the implementation of the treatment, peer scaffolded small groups were formed; peer scaffolders were selected and scaffolds were assigned. Equivalent procedure was employed for comparison condition.

In the experimental and comparison class, three students sit in one desk. Therefore, small groups were formed by joining the six students sitting in two desks. Of the six students, one was the peer scaffolder or group leader and the rest were the learners. In this basis, eight groups were formed. In addition to their sitting arrangement, the number of students that should be assigned in one group was decided based on Light's (1990) and Tzuriel's (personal communication, July 10 ${ }^{\text {th }}$ 2011) recommendation: five to eight students in a group. Accordingly, in EG peer scaffolders $(n=8)$ were randomly assigned to small groups $(n=8)$ each consist of scaffolds $(n=7$ but for two group $n=6)$. Similarly, group leaders $(n=8)$ were randomly assigned to small groups $(n=8)$ each consist of learners $(n=6$ but for one group $n=7)$. The peer scaffolds were students $(n=44)$ who scored lower results than the eight top scorers did. Lot was casted to assign the students into the eight groups. They 
stayed in the same group for two consecutive lessons. Newer groups were formed every two weeks.

\section{b.Controlling Procedure}

Both experimental and comparison group of students were relatively similar in many respects. To mention some, they all came from two schools. They have been taught all subjects other than Amharic in English. They were taught using the same material for equal amount of time and frequency per day. No loss of subjects through dropout occurred during the course of the experiment.

It is worth reminding that, the study was intended to see the effects of peer scaffolding with the teachers' supervision. The teacher could not be totally excluded but his role was limited to monitoring and facilitating. As recent empirical findings have demonstrated the teacher can have an impact on the quality of students' discussion in small-groups, and that the nature of the role assumed by the teacher is crucial for the promotion of successful learning and productive discussion (Meloth \& Deering, 1999; Mercer \& Wegerif, 1999; RaskuPuttonen, Etelapelto, Hakkinen, \& Arvaja, 2002) as cited in Tesfamicheal 2011. During the peer scaffolding activities, an important role was reserved for the teacher. He was present and wandered about the classroom at all times to observe the grammar groups, to coach the students to intervene and provide assistance or guidance on an as-needed base. This influence of the teacher was however, controlled since the same teacher taught both the experimental group and the comparison group.

The purpose of setting comparison group in this research was to exactly trace out peculiar effects of the intervention. It would be advisable for the two conditions to be similar except peer scaffolding programme so that changes could be attributed to the treatment only. There were several variables considered to negatively affect the outcomes of the treatment. One important variable considered was their previous grammar proficiency achievement. Thus, the EG and CG students grammar proficiency result differences in the first semester final exam were checked using independent samples $t$ test.

\section{c.Data Collection Procedure}

One pre-test was administered within a week interval for three consecutive weeks prior to the intervention. This interval was assumed adequate to avoid boredom.

After the two-month intervention another post-test, which were equivalent with the pre-test in length, content and difficulty level, was administered in a weak interval. This was to check students' progress comparing with the baseline data. Nevertheless, to avoid testing threat for validity, the grammar lessons were varied that talks about different issues.

There was range of issues that might affect the reliability of tests. Hence, great care was taken concerning the administration and scoring of the tests in addition to the construction. Hence, both the pre- and post-tests were administered in the opposite shifts. Both the experimental and control groups took the tests in weekend. For each test, adequate time (40 minute) was allotted. The researcher invigilated the students explaining the importance of the tests and creating healthy atmosphere that allow them avoid nervousness and test anxiety.

The social validity questionnaire was designed and translated into Amharic. The translated version of the questionnaire was given to a colleague who was graduated in teaching Amharic. After getting the comments, the translated version was revised and administered. The objective of the questionnaire was well addressed. Since all of the items were answered on a five-point-Likert scale, the students were first briefed how to show their agreement or disagreement using the scales given. They were provided with adequate assistance in case of difficulties, as the researcher was available during administration. They filled the questionnaire. As much as possible, attempts have been made to avoid conditions that might affect the validity and reliability of the instrument.

\section{Data Analysis Techniques}

The changes of the experimental group were judged against the comparison group. Hence, experimental students score in the pre- and post-tests were analyzed using descriptive and inferential statistics compared to control group. The gained scores in the three pre- tests and the other three post-tests were separately calculated to get the students average pre-test and post-test scores. Independent samples $t$ test were employed to compare the test scores of the two groups at the pre and post-test and a paired samples $t$ test for inter group comparison. SPSS was used to calculate the $t$ tests.

The responses to statements of the Likert type scale were scored in such a way that a response indicative of the most favorable impact of the intervention was given the highest score of 5 and that with the most unfavorable effect was given the lowest score 1 . The students' response for each category was summed and expected mean was calculated for each of the five categories. Then one sample t tests were computed to measure the students rating of the social validity of the intervention using the expected mean.

\section{Presentation of Data and Disscusion}

The purpose of the study was to examine the effect of peer scaffolding on students' grammar proficiency development and the participants' appraisal of the intervention session. The results from the data were discussed 
and analyzed to answer the research questions posed. Though presented in questions, it was hypothesized that experimental scaffolders who were participated in peer scaffolding sessions would show greater pre- to postintervention improvement in grammar proficiency than control group who were not involved in peer scaffolding sessions would. Furthermore, it was assumed that experimental students would rate the intervention as socially valid.

Findings

Table 1: Independent samples $t$ test for pre-test scores

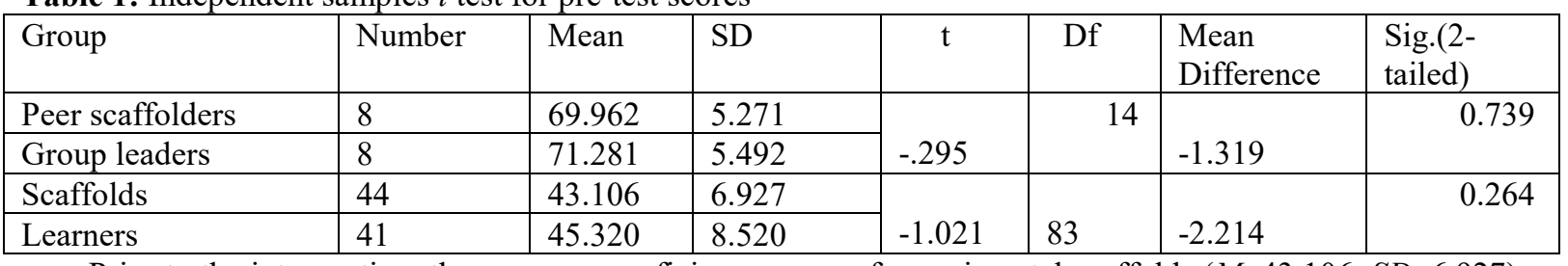

Prior to the intervention, the grammar proficiency score of experimental scaffolds $(M=43.106, S D=6.927)$ a bit less than learners scored $(M=45.320 S D=8.520)$. However, the independent samples $t$ test revealed no statistically significant difference between the scores of scaffolders and group leaders, $t(14)=.296, P>.05$ and scaffolds and learners,t $(83)=1.021, \mathrm{p}>.05$.

The main purpose of the post-test phase was to check weather students' (both in the EG and CG) grammar proficiency result has shown differences after the treatment. Therefore, to judge this, independent samples $t$ tests were computed for the post intervention results of the groups. The findings are presented in table seven.

Table 2: Independent samples $t$ test results for post-test scores

\begin{tabular}{|l|l|l|l|l|l|c|c|}
\hline \multicolumn{1}{|c|}{ Group } & Number & Mean & SD & T & Df & Mean Difference & Sig.(2-tailed) \\
\cline { 1 - 4 } Peer scaffolders & 8 & 79.617 & 4.936 & & & 11.325 & 0.000 \\
\hline Group leaders & 8 & 68.302 & 5.923 & 5.002 & 14 & & 0.136 \\
\cline { 1 - 5 } Scaffolds & 44 & 57.307 & 7.110 & & & & 0.000 \\
\hline Learners & 41 & 48.171 & 5.914 & 5.109 & 83 & & \\
\hline
\end{tabular}

During the post-test the scaffolders and scaffolds higher than their CG counterparts do.Group leaders' score $(M=69.302, S D=5.923)$ was quite less than the CG scaffolders' $(M=79.617, S D=4.936)$. Similarly scaffolds' score $(\mathrm{M}=57.307, \mathrm{SD}=7.110)$ was higher than learners $(\mathrm{M}=48.171, \mathrm{SD}=5.914)$. Simply looking at mean scores presented, one may conclude that the means of scaffolders and scaffolds surpasses that of group leaders and learners after the intervention. However, the extent to which these differences were significant need to be checked. Thus, an independent samples $t$ tests were computed.

As it appears in table two, the independent samples $t$ test showed that the scaffolders' post-test score significantly differs from group leaders', $t(14)=5.002, \mathrm{p}<.001$. Similarily, significant difference was found between the scores of scaffolds and learners, $t(85)=5.914, \mathrm{p}<.001$. was found between the scores of EG and CG learners, $t(85)=5.864, p<.001$.

Result on the post-test rather showed significant differences on the students' grammar achievement score. Though the data clearly tell us the differences in students' grammar achievement in the pre and post-test, it seems ambiguous since it hardly depict which group the EG scaffolds or the CG learner) brought the differences. Therefore, to avoid the ambiguity and arrive at sound judgment, intragroup $t$ tests were carried out for the pre and post scaffolding grammar proficiency results. The results are presented in table 9 below.

Table 3: Paired samples $t$ test results (intragroup $t$ tests)

\begin{tabular}{|l|l|l|l|l|l|l|l|l|l|l|}
\hline Group & \multirow{2}{*}{ No. } & \multicolumn{2}{|c|}{ Pre-test } & \multicolumn{2}{|l|}{ Post-test } & \multicolumn{2}{l|}{ Paired difference } & T & \multirow{2}{*}{ Df } & \multirow{2}{*}{ Sig.(2tailed) } \\
\cline { 3 - 12 } & & $\mathrm{M}$ & $\mathrm{SD}$ & $\mathrm{M}$ & $\mathrm{SD}$ & Mean & SD & & & \\
\hline Scaffolders & 8 & 68.732 & 5.103 & 79.617 & 4.936 & -10.885 & 2.532 & -11.022 & 7 & .000 \\
\hline Group leaders & 8 & 70.973 & 5.247 & 68.302 & 5.923 & -2.671 & 4.375 & 1.272 & 7 & .267 \\
\hline Scaffolds & 44 & 42.023 & 7.889 & 57.307 & 7.410 & -15.284 & 8.554 & -9.304 & 41 & .000 \\
\hline Learners & 41 & 45.753 & 9.760 & 48.171 & 5.914 & -2.418 & 9.477 & -1.525 & 43 & .108 \\
\hline
\end{tabular}

Table three shown that the pre to post increment of mean scores of the EG scaffolders and scaffolds. The scaffolders' post-test score was increased by 10.885.Likewise, the scaffolds' post test score showed 15.284 mean deference as compared to their pre-test score. In proving significance of these changes, the paired sample $t$ test computed for the scaffolders scores asserts significant improvement $(43)=11.022 \mathrm{p}<.001$. The scaffolds' mean score increase was also significant, $t(43)=9.3041, p<.001$.

In the contrary, control learners did not show statistically considerable improvement. The paired samples $t$ tests confirm the difference registered between the pre and post-test was not significant for both group leaders, $\mathrm{t}(7)=1.272 \mathrm{p}>.05$ and the scaffolds $\mathrm{t}(43)=1.525 \mathrm{p}>.05$. These results imply the significant change seen in independent samples $t$ test computed for post-test result was because of the improvement of the mean scores 
of the scaffolds.

\section{Social Validity Questionnaire Result}

At post intervention phase, the scaffolds and scaffolders who were participating in the experimental condition were asked to evaluate the intervention through social validity questionnaire. The results were grouped into five categories: appropriateness, perceived effectiveness, feasibility of procedures, satisfaction and willingness. Onesample $t$ tests were computed to see significant differences of students' rating as compared to the expected mean of each category. The group results are presented in the tables 9-13 below.

Table 4:One sample $t$ test of participants' response regarding the appropriateness of the intervention(Test Value $=6$ )

\begin{tabular}{|l|l|l|l|l|c|c|l|}
\hline Group & Number & Mean & SD & T & Df & Mean Difference & Sig(2-tailed) \\
\hline Scaffolds & 44 & 7.23 & 1.04 & 6.49 & 43 & 1.88 & .000 \\
\hline Scaffoders & 8 & 9.01 & 0.80 & 12.8 & 7 & 3.99 & .000 \\
\hline
\end{tabular}

Item 1 and 2 of the social validity questionnaire enquired whether the participants feel the intervention was acceptable. The mean scores of the scaffold's (6.49) and scaffolders (12.8) response were higher than the expected mean (6). Thus, the scaffold's and scaffolders rate the intervention as acceptable, $t(43)=7.23, p<.001$ and $\mathrm{t}(7)=9.01 p<.001$ respectively.

Table 5: One sample $t$ test of participants' response concerning the effectiveness of Activity Theory (Test Value $=15)$

\begin{tabular}{|l|l|l|l|l|c|c|l|}
\hline Group & Number & Mean & SD & T & Df & Mean Difference & Sig(2-tailed) \\
\hline Scaffolds & 44 & 19.11 & 1.4 & 14.04 & 43 & 5.07 & .000 \\
\hline Scaffoders & 8 & 21.41 & 1.73 & 12.01 & 7 & 6.09 & .000 \\
\hline
\end{tabular}

Item 3,4,5,6 and 7 were regarding perceived effectiveness of the intervention in bringing permanent performance improvement, making students effective and efficacious grammar and arousing interest to do so. The observed mean scores of responses of scaffold's (19.11) and scaffolders (21.41) significantly exceeded the expected value $(15), t(43)=14.03$ and $\mathrm{t}(7)=12.01, p<.001$ respectively.

Table 6: One sample $t$ test of participants' response regarding feasibility of the procedures of Activity System programme (Test Value-15)

\begin{tabular}{|l|l|l|l|l|c|c|l|}
\hline Group & Number & Mean & SD & T & Df & Mean Difference & Sig(2-tailed) \\
\hline Scaffolds & 44 & 17.97 & 1.94 & 7.49 & 43 & 2.98 & .000 \\
\hline Scaffoders & 8 & 21.14 & 1.89 & 8.3 & 7 & 5.99 & .000 \\
\hline
\end{tabular}

In order to elicit students' response to the feasibility of the procedures of the intervention, five items were included in the social validity questionnaire. These were item $8,9,10,11$ and 12 . The EG scaffolders' response mean (17.97) and scaffoders 21.4 significantly exceeds the expected mean (15), $t(43)=7.49, p<.001$ and $\mathrm{t}(7)=8.30, p<.001$.

Table 7: One sample $t$ test of students' response concerning their satisfaction (Test value $=9$ )

\begin{tabular}{|l|l|l|l|l|c|c|l|}
\hline Group & Number & Mean & SD & T & Df & Mean Difference & Sig(2-tailed) \\
\hline Scaffolds & 44 & 12.33 & 1.94 & 12.63 & 43 & 3.44 & .000 \\
\hline Scaffoders & 8 & 13.24 & 1.03 & 15.33 & 7 & 4.56 & .000 \\
\hline
\end{tabular}

Concerning participants' satisfaction, the expected response mean for item 13,14 and 15 was nine. As compared to this value the one sample $t$ test showed the scaffolds' response was higher, $t(43)=12.63$, $p<.001$. Similarly, significant excel was seen for the scaffolders' response, $\mathrm{t}(7)=15.33 \mathrm{p}<.001$

Table 8: One sample $t$ test of participants' response regarding their willingness. (Test value $=9$ )

\begin{tabular}{|l|l|l|l|l|c|c|l|}
\hline Group & Number & Mean & SD & T & Df & Mean Difference & Sig(2-tailed) \\
\hline Scaffolds & 44 & 12.01 & 1.37 & 11.23 & 43 & 2.82 & .000 \\
\hline Scaffoders & 8 & 13.13 & 1.37 & 9.37 & 7 & 4.26 & .000 \\
\hline
\end{tabular}

Item 16, 17 and 18 were aimed at measuring participants' willingness to use peer scaffolding instruction in other contexts and to change their classroom routine for implementing peer scaffolding. Table 8 shows that participants' response scores significantly elevated the expected mean (9). The one sample $t$ test prove significant outshining of scaffolds response, $t(43)=11.23, p<.001$ and scaffolders' response,t(7)=9.37, $p<.001$.

\section{Summary}

The prevailing students' grammar proficiency difficulty initiates this research agenda. Considering factors contributing to this problem, the efficiency of grammar instruction is one major factor. Thus, alternative method, which enhances the effectiveness of grammar proficiency instruction, found to be important. After examining the limitations of the existing instruction and reviewing literature, implementing peer scaffolding model was supposed to alleviate the difficulties and improve students grammar proficiency.

The purposes of this study were examining the effectiveness of peer scaffolding on students grammar 
proficiency and the extent of participants rating of the intervention as socially valid. In order to achieve this goal, attempts were made to test the hypotheses that there is significant pre- to post-test difference in the grammar proficiency performance between students ( EG scaffolds) who were treated with peer scaffolding and those ( CG learners ) who were not provided with such intervention.

A non-equivalent group pre- test-post- test quasi-experimental design was employed to check pre to post between group differences. The participants of the research were $10^{\text {th }} \mathrm{B}(n=52)$ and $\mathrm{E}(n=49)$ students of Tillili Preparatory and General Secondary School. Selecting randomly, $10^{\text {th }} \mathrm{B}$ students received experimental treatment and $10^{\text {th }} \mathrm{E}$ conventional one. Though randomization was applied the EG and CG were not significantly different in age sex, language learning background. Therefore, the outcome resulted in the part of the EG was interpreted as the effect of the independent variable.

Two grammar proficiency tests were prepared and administered before and after the intervention to measure students' grammar proficiency one of which was pre-test used to set baseline data. After the two-month intervention, the other one post- test was administered. Attempts were made to make the entire tests equivalent to each other. The second instrument used was a social validity questionnaire. A five point Likert type scale having eighteen items was prepared to measure the appropriateness, effectiveness, feasibility of the programme and satisfaction and willingness of the respondents' to take part again. It was administered for EG scaffolds $(n=52)$ during the post intervention phase.

The intervention had two components: the scaffolders preparation and peer scaffolding session. First, the scaffolder was trained in fundamentals of peer scaffolding instruction. After they were adequately prepared, they were assigned to eight groups having at least five scaffolders each. The scaffolds $(n=52)$ were randomly assigned into the eight groups. In CG, similar configuration was employed. Similarly, eight groups were formed by assigning eight group leaders who scored higher than the learners did. The group leaders, however, were not trained in the peer scaffolding principles. As a result, no scaffolding programme session schemed except fulfilling the basic interaction condition.

The EG learners were assisted by trained scaffolders and interact fulfilling the peer scaffolding criteria for eight sessions covering two grammar lessons(simple past and present perfect tense) each consisting of various sub sections. The teacher was thought the experimental group using activity system model through scaffolding facilitating monitoring and kipping the content valid in both conditions.

The mean scores of the two tests in pre and post-tests were calculated for comparison. An independent samples $t$ test was computed in both phases. The independent samples $t$ test result in the pre-test for the EG and $\mathrm{CG}$ was not significant. However, a significant difference was reported in the post-test. Though little increment in mean value was seen, the $t$ test for CG proves the change was not statistically significant.

The EG objects were asked to rate the social validity of the intervention. They rated that peer scaffolding programme was appropriate, effective and enjoyable. They were also positive towards the clearness and feasibility of the procedures. They confirmed that they enjoyed and satisfied by their participation and willing to have it again in other context.

\section{Conclusion}

Despite the limitations of this study, it does support conclusions that there are potential benefits to incorporating peer scaffolding interventions implemented via scaffolder discussion within the natural school setting. Results of this study have indicated that training students in peer scaffolding programme is an effective way to prepare them for a scaffolding instruction model style that enhances the EG objects learning how to learn skills and, in consequence, their learning and achievements in grammatical proficiency. The finding of the study shows a more competent scaffolder who has been taught how to scaffold and has actively used the peer scaffolding through scaffolding instruction principles with scaffolders becomes a better learner.

In theoretical aspect the study extend the Rachel R. Van Der Stuyf notion of scaffolding by showing scaffolders cognitive improvement through scaffolding peers. Rchel's focus in particular, for instance, is on the benefit of the scaffold through receiving adequate scaffolding instruction. However, the findings of this study adds important dimension of this by further considering the benefits of thescaffolder for himself or herself in the scaffolding process. This study strengthens the contribution of Tzuriel and Shamir's (2006) work, which suggests an additional theoretical level to Rachel R. Van Der Stuyf perspectives by proving alternative modality, scaffolding for peer, as a powerful strategy to facilitate one's own cognitive processes.

Practically the result depicts peer scaffolding can effectively be implemented in secondary school by training more scaffolder to successfully scaffold him/herself and fellows. This was supported by the findings of the social validity assessment. Given the grammar proficiency difficulties of the students peer scaffolding programme was appropriate. The programme was effective in achieving the planned goal: participants grammar proficiency achievement. The procedures employed in scaffolding programme were feasible. As a result, students were satisfied by participating as a learner. Furthermore, they were willing to involve in similar modality of peer scaffolding programme found to be acceptable and applicable. Thus, it is possible and 
promising to incorporate scaffolding instruction in language classroom particularly in learning/teaching grammar lesson.

\section{References}

Abraham Degu (2008). The Effectiveness of the Teaching of English Grammar as a Foreign Language through the Integration of Form,Meaning and Use.(Unpublished M.A.Thesis).Addis Ababa Univesity.

Applebee, A. N. and J. A. Langer,( 1983). 'Instructional scaffolding: Reading and writing as natural language activities. Language Arts, 60/2.

Applebee, A. N. (1986). 'Problems in process approaches: Towards a reconceptualization of process instruction' in A. R. Petrosky and D.

Bruner, J. (1978). 'The role of dialogue in language acquisition' In A. Sinclair, R., J. Jarvelle, and W. J.M. Levelt (eds.).The Child's Concept of Language. New York: Springer-Verlag.

Celce-Murcia M. (88) Techniques and Resources in Teaching Grammar. Oxford: Oxford University Press.

Cunningsworth, A. (1984). Evaluating and Selecting EFL TeachingMaterials. Oxford: Heineman Books Ltd.

Freman, D. (1986). Teaching Grammar. In Celce-Murcia. M. 1991 (ed). Teaching English as a Second or Foreign Language. P. 277-296. Los Angeles: Heinle and Heinle Publishers.

Harmer, J. (1987). Teaching and Learning Grammar. New York: Longman Ltd.

Krashen, S. (1985). The Input Hypothesis. New York: Long Ltd.

Martin, B. et. al., (1994). Grammar and the Language Teacher. London: Prentice Hall International Ltd.

Prabhu, N.S. (1987). Second Language Pedagogy. Oxford: Oxford University Press.

Raymond, E. (2000). Cognitive Characteristics. Learners with Mild Disabilities (pp. 169-201). Needham Heights, MA: Allyn \& Bacon, A Pearson Education Company. Social Development Theory. (No date). Retrieved November 3, 2002, from http://tip.psychology.org/vygotsky.html

Rechards, J.C., and Rodgers, T.S. (2001). Approaches and Methods in Language Teaching. Cambridge: Cambridge University Press.

Seyoum H, ( 2008).Comparative study of grammar teaching methods employed by televised teacher and nonplasma school teachers (Med unpublished thesis Addis Abeba University).

Sato, C. 1986. 'Conservation and interlanguage development: Rethinking the connection' in R. Day (ed.) Talking to Learn: Conversation in Second Language Acquisition. Rowley, Mass.:Newbury House. Joseph Foley, Department of English Language and Literature, National University of Singapore 102 Joseph

Stern, H.H. (1983). Fundamental Concepts of Language Teaching. Oxford: Oxford University Press.

Tesfamicheal, G. (2011).The Effect of Peer-mediation on Students' Reading Comprehension development.Unpublished M.Ed.Thesis.Bahir Dar University. 